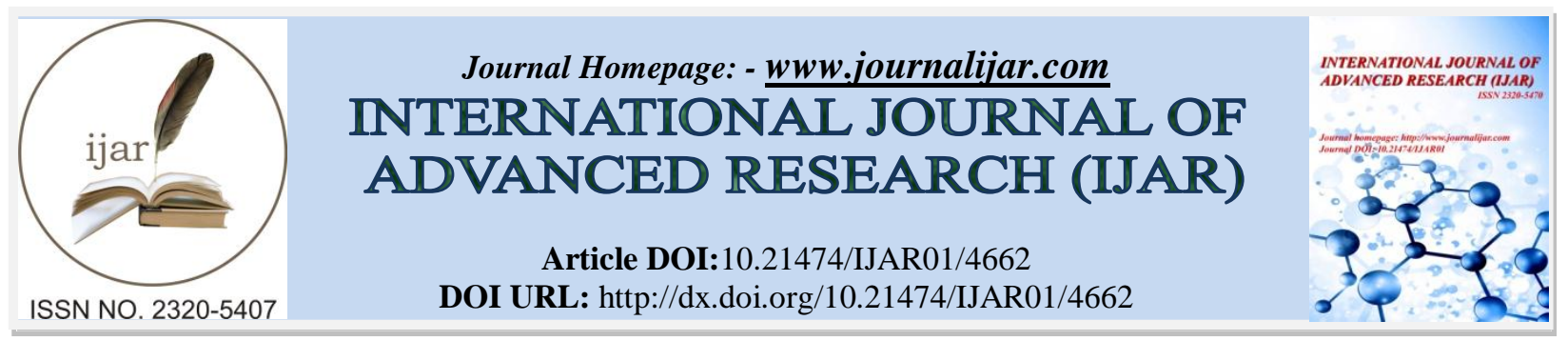

RESEARCH ARTICLE

\title{
PREVALENCE OF LOWER CROSSED SYNDROME IN YOUNG ADULTS: A CROSS SECTIONAL
} STUDY.

\section{Shriya Das ${ }^{1}$, Bibhuti Sarkar ${ }^{2}$, Rachana Sharma ${ }^{3}$, Malika Mondal ${ }^{1}$, Pravin Kumar ${ }^{4}$, Pallavi Sahay ${ }^{5}$.}

1. Professional Trainee, Department of Physiotherapy, National Institute for Locomotor Disabilities (Divyangjan), B. T. Road, Bonhoogly, Kolkata-700090, West Bengal, India.

2. Demonstrator (PT), Department of Physiotherapy, National Institute for Locomotor Disabilities (Divyangjan), B. T. Road, Bonhoogly, Kolkata-700090, West Bengal, India.

3. Senior Professional Trainee, Department of Physiotherapy, National Institute for Locomotor Disabilities (Divyangjan), B. T. Road, Bonhoogly, Kolkata-700090, West Bengal, India.

4. Assistant Professor ( PT), Department of Physiotherapy, National Institute for Locomotor Disabilities (Divyangjan), B. T. Road, Bonhoogly, Kolkata-700090, West Bengal, India.

5. Physiotherapist, Department of physiotherapy, National Institute for Locomotor Disabilities (Divyangjan), B.T. ROAD, Bonhoogly, Kolkata-700090, West Bengal, India.

\section{Manuscript Info}

\section{Manuscript History}

Received: 23 April 2017

Final Accepted: 27 May 2017

Published: June 2017

Key words:-

Lower crossed syndrome, Abdominals,

Gluteus Maximus, Iliopsoas, Spinal

extensors, Cross-sectional study.

\section{Abstract}

Background: Lower crossed syndrome (LCS) is a musculoskeletal imbalance characterized by specific patterns of muscle weakness (Abdominals and Gluteus Maximus) and tightness ((iliopsoas and spinal extensors) that crosses between the dorsal and the ventral sides of the body. This postural imbalance among young individuals can lead to Low back pain in future. Hence, this study aims to find out the prevalence of lower crossed syndrome in young individuals in male and female subjects between the age group of 21 to 31 years.

Methods: Weakness of abdominals and hip extensors muscles and tightness of hip flexors and spinal extensors muscles were measured on 200 healthy adults (117 male, 83 female). Results: SPSS version 23 was used for data analysis and result suggests that females are more prevalent to develop lower crossed syndrome than male of the same age group. 30 female volunteers out of 83 volunteers and 14 male volunteers out of 117 volunteers have LCS. Conclusion: Prevalence of developing lower crossed syndrome among young females is more than young males of same age group (21 yrs to 31 yrs).

Copy Right, IJAR, 2017,. All rights reserved.

\section{Introduction:-}

The Lower Crossed Syndrome (LCS) is defined as "S" shaped posture of the lower back characterized by tight hip flexors and lower back muscles paired with weak abdominal muscle and gluteus maximus muscle, also referred as distal or pelvic crossed syndrome. ${ }^{13}$ In LCS, tightness of the thoraco-lumbar extensors on the dorsal side crosses with tightness of the iliopsoas and rectus femoris. Weakness of the deep abdominal muscles ventrally crosses with weakness of the gluteus maximus and medius. This pattern of imbalance creates joint dysfunction, particularly at the L4-L5 and L5-S1 segments, SI joint and hip joint. ${ }^{13}$ 
Specific postural changes seen in LCS include anterior pelvic tilt, increased lumbar lordosis, lateral lumbar shift, lateral leg rotation and knee hyperextension. If the lordosis is deep and short, then imbalance is predominantly in the pelvic muscles; if the lordosis is shallow and extends into the thoracic area, then imbalance predominates in the trunk muscles. ${ }^{13}$ Janda considered muscle imbalance to be an impaired relationship between muscles prone to tightness or shortness and muscles prone to inhibition. According to author there are mainly two types of muscles present in our body, which are postural muscles such as iliopsoas, quadrates lumborum, erector spinae, rotators of back and phasic muscles such as abdominals, hip extensors etc. He noted that predominantly static or postural muscles have a tendency to tighten. In various movements, they are activated more than the muscles that are predominantly dynamic and phasic in function, which have a tendency to develop weakness. ${ }^{13,28}$

People in the age group of late teens to 40 years are highly active in daily life and are exposed to various stresses. Unlike in the elderly, the age-related changes are minimal in this age group ${ }^{17}$ Burton A.K in the year of 1996 shown that the prevalence of developing low back pain in young adolescents is similar to that of adults. ${ }^{4} \mathrm{G} T$ Jones et al in his study shows that lifetime prevalence as high as $70-80 \%$ by 20 years of age. ${ }^{22}$ In addition, several studies have calculated new onset rates of around $20 \%$ over a $1-2$ year period. ${ }^{22}$ Birger et al concluded that $85 \%$ of low back pain has an origin due to muscle imbalance commonly due to long term postural faults called lower crossed syndrome. ${ }^{9}$

One of the more intriguing physical medicine theories is that the fundamental imbalance between postural and phasic muscles in and around the pelvis perpetuates imbalance, strain and altered movement patterns, which accounts for the re-injuring of these key structures. ${ }^{5}$

Janda noticed that due to prolonged static postures, such as sitting at a desk all day, the hip flexors become shortened or tight. Therefore, the brain will automatically start to shut down or inhibit the glutei muscles which are on the opposite side. Now, the imbalance pattern promotes increased lumbar lordosis because of the forward pelvic tilt and hip flexion contracture, and over activity of the hip flexors compensating for the weak abdominals. ${ }^{5}$

Hip extension would be limited due to a tightened psoas and the presence of an inhibited antagonistic gluteus maximus would create a poor quality of hip extension because the contra lateral lumbar erector spinae and ipsilateral hamstrings would have to become overactive and eventually tight to perform the necessary hip extension instead of the gluteus maximus. ${ }^{3,5,13}$

Low back pain is a universal problem and lower crossed syndrome is one of the threatening combinations of biomechanical muscle imbalance due to excessive stress it places on the structures of lower back. People with such postural imbalance frequently complain of lower back pain and if it is left unchecked, this postural imbalance can generate a chronic pain condition of lower back that becomes more difficult to correct in later stages.

There are lack of literature evidence, which can show the prevalence of lower crossed syndrome in young adults (males and females). Hence, this study was designed to identify the population at risk of developing lower crossed syndrome which in long term may develop low back pain (LBP) and an appropriate cost effective corrective measure of the musculatures can be taken at an early stage which will serve to be a primary prevention strategy in preventing risk of LBP. Therefore, the present study intended to find out the prevalence of lower crossed syndrome in young males and females within the age group of 21 yrs to $31 \mathrm{yrs}$.

\section{Methodology:-}

This prospective cross sectional study evaluated the prevalence of lower crossed syndrome in young adults included from students, staff and patient caregivers visiting to NILD, (Divyangjan), Kolkata, India between April, 2016 to December, 2016. Scientific and Ethical approval was taken from Institute Ethical Committee (IEC) before the commencement of the study. A stratified purposive sampling was done to include 200 healthy male and female volunteers within $21 \mathrm{yrs}$ to $31 \mathrm{yrs}$ of age with Physical Component Summary (PCS) and Mental Component Summary (MCS) score of SF36 scale above 50. Informed consent form (which also includes permission to use their data and photograph for presentation and publication purpose) written in their preferred language (English/ Hindi/ Bengali) was obtained from volunteers who agreed to participate.

The volunteers with history of back surgery or lower limb surgery, trauma to back or lower extremity, low back pain within the last six months, diagnosed cases of rheumatoid arthritis or osteoarthritis of the spine or hips, spinal deformity, spasm of paraspinal muscle, neurological disease, any history of cardiovascular diseases such as 
hypertension, stroke, or other cardiac disorders, females with pregnancy and uncooperative volunteers were excluded. ${ }^{5}$

Total 230 healthy individuals were approached with the proposal of study. 16 individuals refused to participate. Another fourteen individuals were excluded out of which three were having spinal deformity \& 11 had gone through a period of low back pain in last 6 months.

Demographic data including age, sex, height, weight, Body Mass Index (BMI) and occupation were collected from 200 healthy individuals and stratified into two strata according to gender (female and male). Short Form- 36 scale (SF-36) (English/Bengali Version) was evaluated and filled by a physiotherapist (S.D) by asking questions from volunteers. ${ }^{6,30,34}$

Prior to the evaluation of muscle length and strength, all the volunteers performed warm up exercises under therapist's supervision (M.M) with 10 repetitions of back stretches in side flexion and rotation and a 5-minute walk at self determined pace around the research venue. ${ }^{13}$

Length of bilateral Iliopsoas muscle was measured by Modified Thomas test using Universal Goniometer. Length of spinal extensor muscle was checked by non elastic measuring tape. ${ }^{25,26,29}$ Strength of abdominal muscle and bilateral Gluteus maximus Muscle were evaluated according MRC grading of manual muscle testing. All these measurements were carried out by a graduate physiotherapist. ${ }^{7,19,22,33}$ 


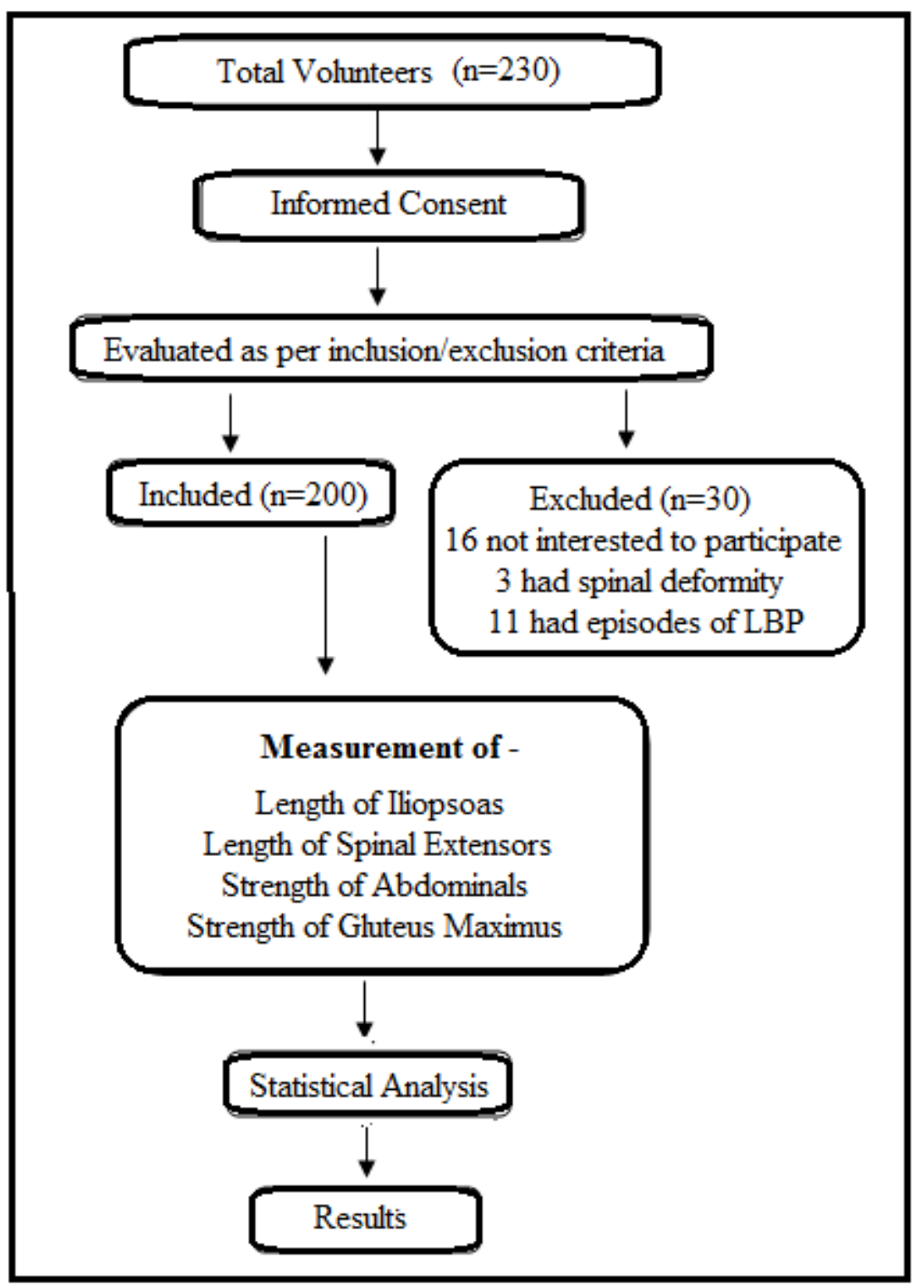

Fig.1:- Flow diagram

Measurement of iliopsoas muscle length ${ }^{26}$ :-

The volunteer was instructed to lie in supine with half of the thigh out of the couch while the therapist standing by the tested table. Lumbar spine was checked for excessive lordosis. The volunteers were instructed and demonstrated to pull (flex) and hold the non tested hip in flexed position, bringing the knee close to the chest to flatten out the lumbar spine and to stabilize the pelvis. One researcher (S.D) measured the length of opposite side iliopsoas with a universal goniometer by keeping the fulcrum over greater trochanter, movable arm kept parallel to the lateral boarder of femoral shaft and stationary arm parallel to the tested table. The test was done on both sides. The iliopsoas was considered tight if hip extension angle less than $15^{\circ}$. 


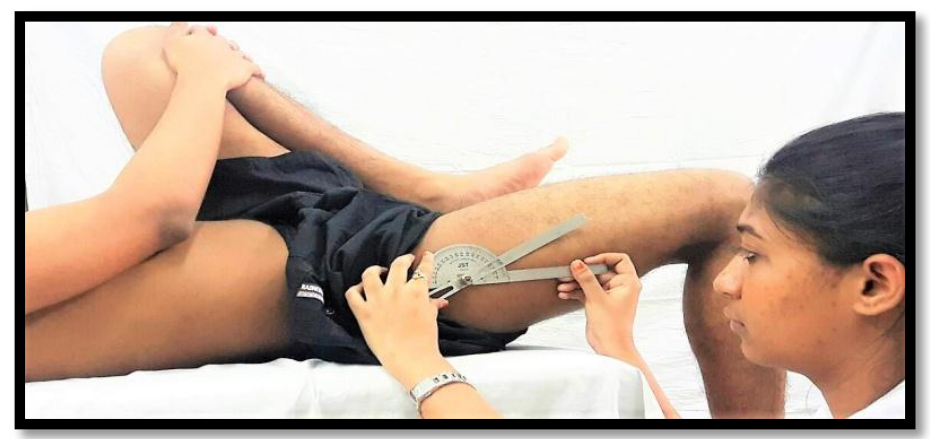

Fig.2:-Iliopsoas muscle length testing by universal goniometer

Measurement of strength of abdominal muscle ${ }^{19,22}$ :-

Abdominal muscle strength was measured by positioning the volunteers in supine lying with both hip and knee flexed and hands clasped behind the head (For Grade-V) (Fig: 3), arms crossed over the chest (for Grade-IV) (Fig: 4) and with arms outstretched in full extension above the plane of body (For Grade-III) (Fig: 5). Therapist(S.D) was standing at side of the table at level of volunteer's chest to ascertain scapular clearance from table during test. Then the volunteers were instructed to flex the trunk through full range of motion. A trunk curl up was emphasized until scapula clears the table. Instruction was given as "Tuck your chin and bring your head, shoulders and arms off the table, as in a sit up".

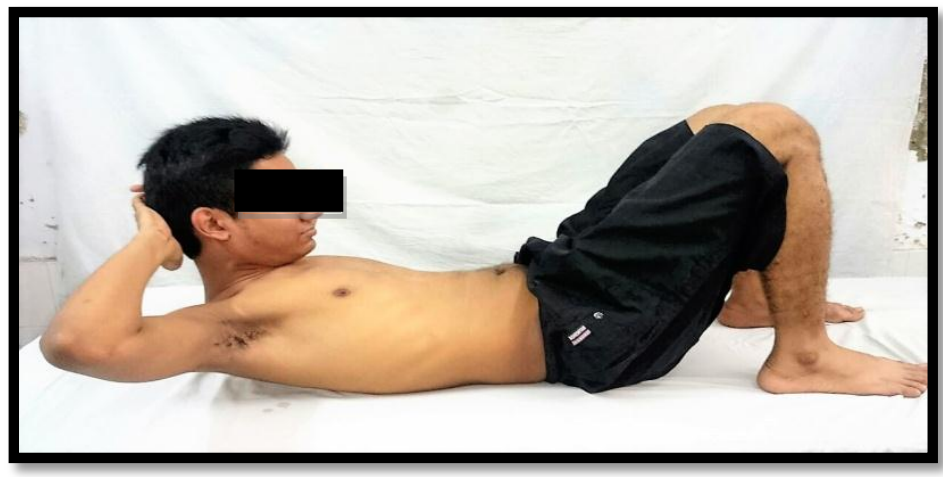

Fig3:- Abdominal muscle strength testing (Grade V)

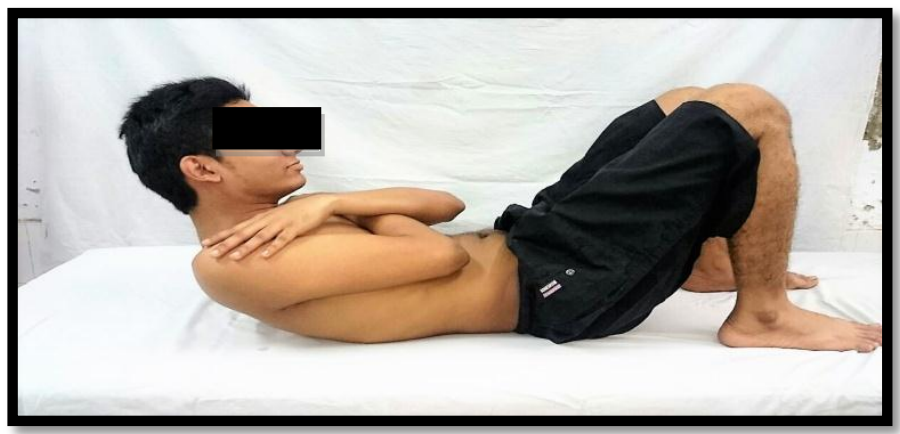

Fig.4:- Abdominal muscle strength testing (grade IV) 


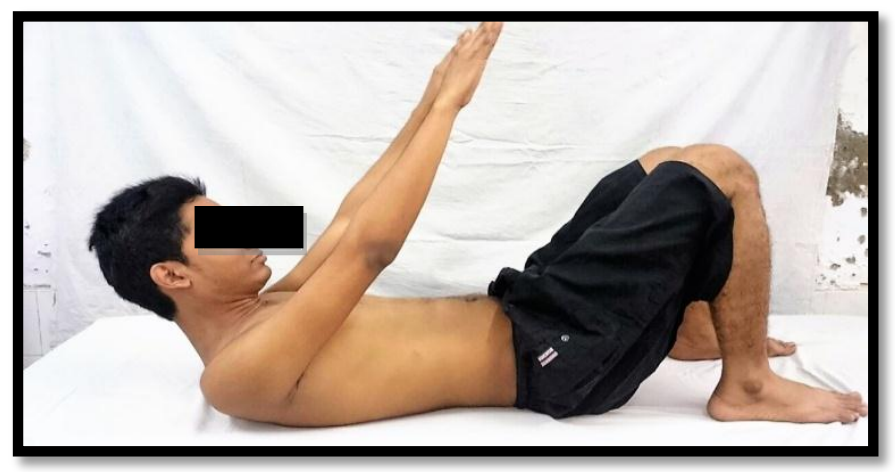

Fig 5:-Abdominal muscle strength testing (Grade III)

\section{Measurement of length of spinal extensors muscle ${ }^{26}$}

The volunteers were instructed to stand erect with the cervical, thoracic, and lumbar spine in $0^{\circ}$ of lateral flexion and rotation. Spinous process of $\mathrm{C} 7$ and $\mathrm{S} 1$ vertebrae was marked by a skin marking pencil and distance between two processes was measured by a tape measure. The pelvis was then stabilized by keeping the therapist (S.D) hand over PSIS to prevent anterior tilt of the pelvis. Instruction was given to the volunteers to bend forward gradually while keeping the arm relaxed maintaining equal load on both feet. The motion was stopped when resistance to additional flexion is experienced by the volunteer and the therapist feels the pelvis start to tip anteriorly. Then the distance between the two spinous processes were again measured (Fig; 6). The difference between the first and second measurement indicates the amount of thoracic and lumber flexion. The length of muscle was considered normal when it is equal to $10 \mathrm{~cm}$.

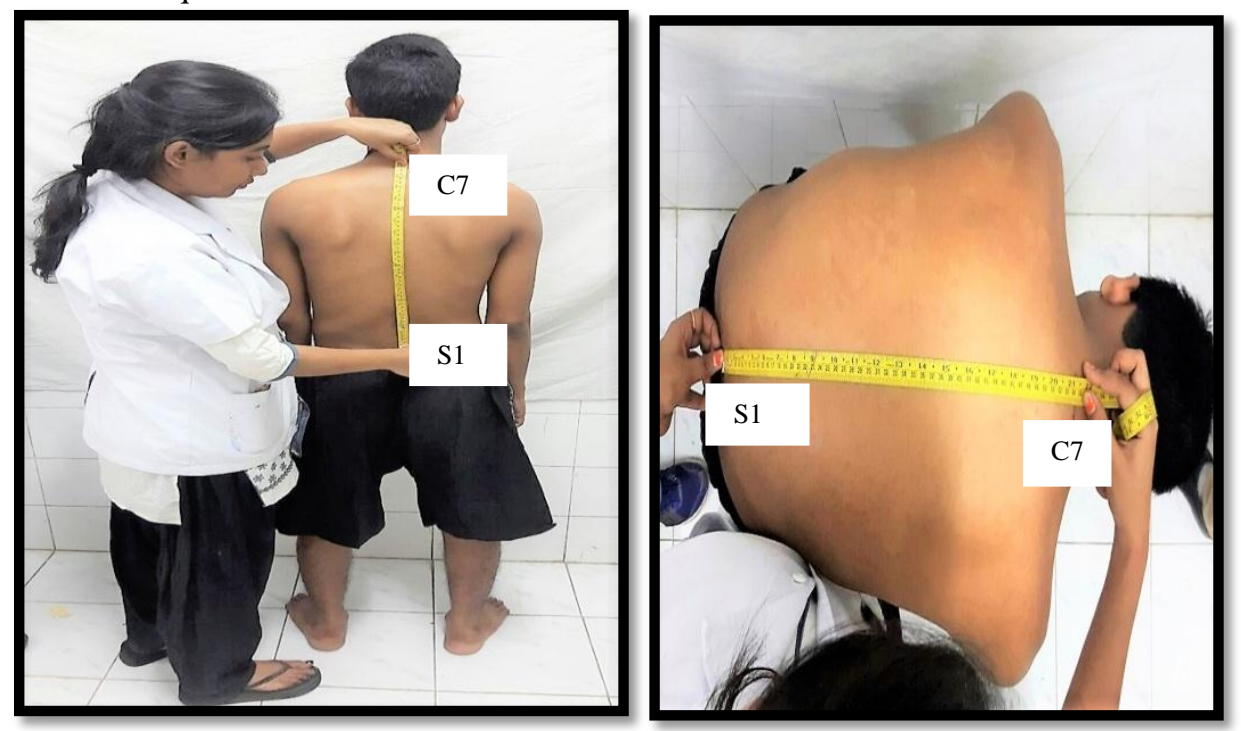

Fig.6:- Spinal extensors length measurement

Measurement of gluteus Maximus strength ${ }^{19,22}$ :-

Volunteer asked to lie in prone position with knee flexed to 90 degree. Therapist (S.D) was in standing position on the tested side at the level of pelvis. Pelvis was stabilized by applying downward pressure at the low back by one hand of the therapist. The volunteers were instructed to extend the hip maintaining the knee flexion at $90^{\circ}$ (blue arrow in fig). Resistance was applied (mild resistance for Grade-IV and maximum for Grade-V) (Fig: 7) by the therapist(red arrow in fig.) manually against the lower part on the posterior thigh in the direction of hip flexion so that the volunteer could complete the full range of hip extension. Then the strength of gluteus maximus was graded according to MRC grading. 


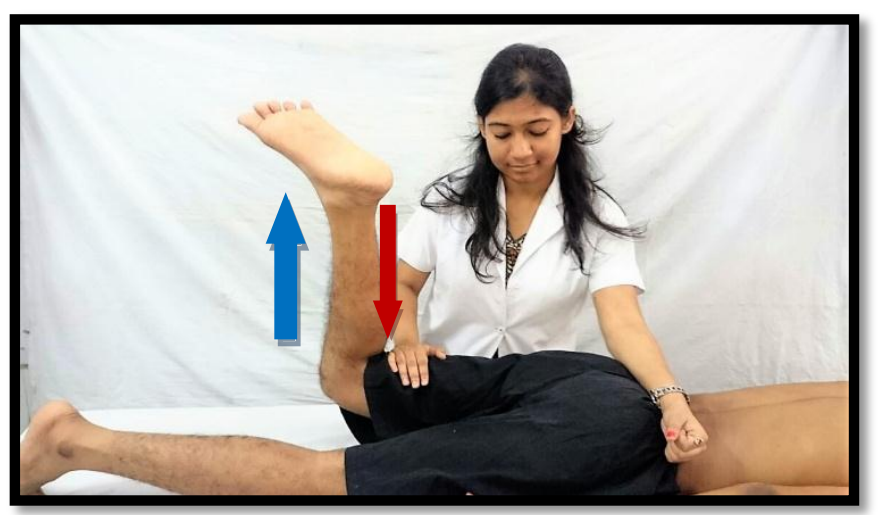

Fig. 7:-Measurement of Gluteus maximus strength

\section{Statistical Analysis:-}

Data were analyzed using SPSS version 23 software. Fisher t-test was used to analyze the demographic data (age, height, weight $\&$ BMI) of both genders. Descriptive statistics was used to determine the frequency of lower crossed syndrome in male and female volunteers. Descriptive statistics were also used to find out the frequency of spinal extensors and iliopsoas tightness, abdominals and gluteus maximus weakness in male and female volunteers. Chisquare test was used to find out homogeneity of proportions of males and females having tight spinal extensors/ iliopsoas and weak abdominals/gluteus maximus. The tests were applied at $95 \%$ confidence interval and level of test was set at 0.05 .

\section{Results:-}

Statistically insignificant difference was found in mean age in both groups. There was statistically significant difference found in mean height, weight and BMI in both groups.

The values of significance for both genders are shown in table 1 .

Chi square test showed highly significant difference in the strength of abdominal muscle in male and female with the $\mathrm{p}$ - value of $(\mathrm{p}=0.001)$ (Table-2). The result is showing that prevalence of weak abdominal muscle in female is more than male of same age group.

Chi square test showed significant difference in the strength of right gluteus maximus muscle in male and female with the $\mathrm{p}$-value of $(\mathrm{p}=0.0001)$. Thus prevalence of right side gluteus maximus muscle weakness in female are more than male of same age group and significant difference in the strength of left gluteus maximus muscle between male and female were found with the $\mathrm{p}$ - value of $(\mathrm{p}=0.0035)$. The result shows that prevalence of left sided gluteus maximus muscle weakness in female are more than in male of same age group (Table-3).

Chi square results showed that there was statistically significant difference in spinal extensors length between male and female with the $\mathrm{p}$ - value of $(\mathrm{p}=0.021)$ (Table.4).

Chi square results showed that there was statistically insignificant difference in right sided iliopsoas length in male and female with the $\mathrm{p}$ - value of $(\mathrm{p}=0.345)$ by accepting $\mathrm{H}_{0}$ at $5 \%$ level of significance and there was statistically significant difference in left sided iliopsoas length between male and female with the $\mathrm{p}$ - value of $(\mathrm{p}=0.0325)$ (Table4).

To test the homogeneity of proportions of males having lower crossed syndrome and that of females having lower crossed syndrome, chi-square test was used. The $\mathrm{p}$-value $(\mathrm{p}=0.001)$ shows that the difference is statistically significant (Table-5).

\section{Discussion:-}

One of the most important risk factor of low back pain in young population is muscular imbalance. Lower crossed syndrome (LCS) is a muscular imbalance that includes tightness of hip flexors, lower back muscles and weakness of abdominals, gluteus maximus muscle; which alter the biomechanical force distribution in lower back region and that may lead to chronic low back pain. ${ }^{12,14}$ There are lack of literature which can state the prevalence of LCS among 
young adults in both genders. So, the present study was conducted with an aim to find out the prevalence of Lower crossed syndrome among young individuals and the prevalence of tight and weak structures among males and females.

200 healthy volunteers with age range of 21 years to 31 years were recruited in this study. The demographic data (age, gender, height, weight and BMI) were analyzed to see the homogeneity between genders by fisher t-test which revealed statistically significant difference in height, weight and BMI and statistically insignificant difference in age between both genders.

After analyzing the data it was found that prevalence of abdominal weakness among females are more than males. Among 83 female volunteers 63 (75.9\%) were having abdominal weakness and among 117 male volunteers 50 $(42.7 \%)$ were having abdominal weakness (Table.2 and Fig no. 3, 4 and 5).

Janda believed that there are three important factors in muscle tightness (Janda 1993) which are muscle length, irritability threshold and altered recruitment. Muscles that are tight usually are shorter than normal and display an altered length-tension relationship. ${ }^{16}$ Muscle tightness leads to a lowered activation threshold or lowered irritability threshold, which means that the muscle is readily activated with movement (Janda 1993). Movement typically takes the path of least resistance, and so tight and facilitated muscles often are the first to be recruited in movement patterns. Tight muscles typically maintain their strength, but in extreme cases they can develop weakness. ${ }^{16}$

Helewa A et al (1981) have stated clear difference in skeletal muscle mass and type of muscle fibre in males and females. They stated that incidence of muscle weakness in female is higher than male because males have significantly greater muscle mass and lower body fat as compared to the females. They also stated that slow twitch muscle fibers are predominant in females where first twitch muscle fiber predominant in male. This is one of the reasons that muscle strength is found more in males than female in same age group in this study. ${ }^{11}$

On analyzing the data it was found that there was significant difference in gluteus maximus strength in male and female with p value of 0.001 (Table 3 and Fig 7), which show prevalence of hip extensors weakness in females are higher than males. Among 83 female volunteers $73(87.9 \%)$ were having right sided gluteus maximus muscle weakness and among 117 male volunteers 67 (57.2\%) volunteers having right sided gluteus maximus muscle weakness. On the other hand, 62 (74.6\%) female and 57 (48.7\%) male volunteers having left sided gluteus maximus weakness. This study result explains that females are more prevalent to develop weakness in gluteus muscle than males.

Mills M et al (2015) suggested that restricted hip flexor muscle length is theorized to decrease neural drive to the hip extensor musculature. Specifically, reciprocal inhibition of the gluteus maximus, secondary to "over activity" of the hip flexor muscle group has been implicated to occur and lead to lower extremity injury ${ }^{24}$ Reciprocal inhibition is theorized to lead to an increased reliance on the secondary hip extensor muscles, such as the hamstrings and hip adductors to produce hip extension torque, clinically referred to as "synergistic dominance" 1,27,34

Luyerink et al (2000) stated that females sat with a more anteriorly rotated pelvis, less lumbar flexion and very little trunk flexion. Conversely, males sat with a posteriorly rotated pelvis, greater lumbar flexion and more forward leaning trunk postures while performing seated office work. Women also positioned their bodies in a different location relative to the pivot point when sitting on a chair with a back rest. This is evident in the differences in centre of mass placement as well as the location of the hip joint with respect to the pivot point of a chair. Taken as a whole, these findings suggest that men tended to slouch against the back rest while females perched closer to the front of the seat pan. 21

Statistically significant difference was found in spinal extensor length between healthy male and females with the $\mathrm{p}$ value of 0.02 (Table 4 and Fig 6). Among 83 healthy female volunteers 54 (65\%) were having tight spinal extensors and among 117 male volunteers 57 (48.7\%) volunteers were having tight spinal extensors.

Muscle tightness results from an increase in tension from active or passive mechanisms among normal population. Actively, a muscles can become shorter due to spasm or contraction. On the other hand, a muscle can passively become shortened through postural adaptation or scarring. Regardless of the cause, tightness limits range of motion and may create a muscle imbalance. During periods of rapid growth, soft tissues such as muscles and ligaments are 
unable to keep pace with the rate of bone growth, resulting in muscle imbalances and a decrease in flexibility in young population. ${ }^{17}$

Kendall believes that back extensor muscle develops tightness because of abdominal muscle weakness and prolonged sitting posture. There is a significant but weak association between back extensor muscle length and hip extensor muscle strength. ${ }^{19 \mathrm{~s}}$

This study demonstrated insignificant difference between males and females in right sided hip flexors length with the $\mathrm{p}$ value of 0.345 but left sided iliopsoas length shows significant difference in male and female with the $\mathrm{p}$ value of 0.032 (Table 4 and Fig 2).

Ashmen K J et al (1996) have stated that decreased iliopsoas muscle length and strength is one of the most leading factor of mechanical low back pain. Because iliopsoas muscle attaches to the pelvis and lumbar spine, tightness of this muscle causes increased lumbar lordosis and weakness of this causes decreased lumbar lordosis, which, in turn, may result in $\mathrm{LBP}^{2}$

Janda had found some characteristic patterns of muscle imbalance in children as young as 8 years (Janda 1989b). Muscle tightness increases between ages 8-16 and then remains constant. He further noted that imbalances in children begin in the upper extremity as opposed to the lower extremity, as is seen in adults. He believed these patterns of muscle imbalance are systematic and predictable because of the innate function of the sensori-motor system. Subsequently, adaptive changes within the sensori-motor system affect the entire system, most often progressing proximally to distally. This muscular reaction is specific for each joint, suggesting a strong relationship between joint dysfunction and muscle imbalance (Janda 1986a). Janda felt that muscle imbalance in today's society is compounded by stress, fatigue and insufficient movement through regular physical activity as well as a lack of variety of movement (Jull and Janda 1987). He noted that most repetitive movements reinforce the postural system and neglects the phasic system which may lead to imbalance. ${ }^{13,14,15}$

Females in general have lower total muscle mass than males and also have lower muscle mass in comparison to total body mass. ${ }^{23}$ Males convert more of their caloric intake into muscle and expendable circulating energy reserves, while females tend to convert more into fat deposits. As a consequence, males are generally physically stronger than females. While individual muscle fibers have similar strength between male and female, males have more fibers as a result of their greater total muscle mass. ${ }^{36}$ Males remain stronger than females, when adjusting for differences in total body mass, due to the higher male muscle-mass to body-mass ratio. ${ }^{36}$ The greater muscle mass is reported to be due to a greater capacity for muscular hypertrophy as a result of higher levels of circulating testosterone in males. ${ }^{23,36}$ When the hip flexors are excessively tight they cause exaggerated pelvic anterior tilt. The lumbar spine becomes excessively arched and the thoracic spine develops a kyphotic (rounded/hunch back) alignment, which can also lead to forward head posture. Tight hip flexors can begin to do the abdominals' work and make it almost impossible to benefit from some abdominal exercises. Tight hip flexors cause the primary hip extensors to become lengthened and weakened because of their agonist-antagonist relationship. ${ }^{28,32}$

Janda found that muscles have a tendency to be either tight or weak in dysfunction. They are prone to tightness because of overload resulting from poor posture and ergonomics. Muscles that are prone to tightness are sometimes found to be weak, while muscles prone to weakness are sometimes found to be tight. Janda in his LCS model has stated that Hip flexors muscle and spinal extensors muscles are prone to develop tightness because these muscle are tonic in nature as well gluteus maximus and abdominal muscles are prone to develop muscle weakness because these are phasic in nature. ${ }^{12,16}$

After analyzing all the outcome variables it was evident that abdominal and gluteus maximus muscle are weak and hip flexors and spinal extensors muscle are tight in female and male participants included in this study. Biomechanical alteration of these muscles leads to muscle imbalance which is named as lower crossed syndrome. In this study, $44(22 \%)$ volunteers out of 200 healthy adults are affected by lower crossed syndrome with a prevalence of $22 \%$. Among 83 female volunteers 30 females (36\%) and among 117 male volunteers 14 (11.9\%) volunteers are affected by lower crossed syndrome.

Lower crossed syndrome in young population increase the incidence of mechanical low back pain and lower extremity risk of injury especially in hip, knee and ankle as abnormal motor recruitment of muscles because of 
muscle tightness and weakness. Therefore clinical identification and prevention of occurring lower crossed syndrome among young individual is highly needed for future pathology.

Table.1:- Demographic summary.

\begin{tabular}{|c|c|c|c|c|c|}
\hline Variables & TOTAL $(\mathbf{n}=\mathbf{2 0 0})$ & MALE $(\mathbf{n}=\mathbf{1 1 7})$ & FEMALE $(\mathbf{n}=\mathbf{8 3})$ & t- Value & p-value \\
\hline Age & $24.73 \pm 2.076$ & $24.89 \pm 3.08$ & $24.02 \pm 3.02$ & 0.88 & 0.37 \\
\hline Height & $160.9 \pm 8.6$ & $165.99 \pm 8.19$ & $154.67 \pm 4.9$ & 11.2185 & 0 \\
\hline Weight & $61 \pm 10.9$ & $66.8 \pm 10.5$ & $52.9 \pm 6.9$ & 10.6192 & 0 \\
\hline BMI & $23.49 \pm 3.4$ & $24.4 \pm 3.49$ & $22.1 \pm 2.78$ & 4.9509 & 0.0000016 \\
\hline
\end{tabular}

Table 2:-Frequency distribution of abdominal muscle strength.

\begin{tabular}{|c|c|c|c|c|}
\hline & Female $(\mathbf{n}=\mathbf{8 3})$ & Male $(\mathbf{n}=117)$ & Total $(\mathbf{n}=\mathbf{2 0 0})$ & p-value \\
\hline Weak & $63(75.91 \%)$ & $50(42.74 \%)$ & 113 & $\mathbf{0 . 0 0 1}$ \\
\hline Normal & $20(24.09 \%)$ & $67(57.26 \%)$ & 87 & \\
\hline
\end{tabular}

Table 3:-Comparison of frequency distribution of Muscle strength.

\begin{tabular}{|c|c|c|c|c|c|}
\hline & & \multicolumn{4}{|c|}{ MMT GRADE } \\
\hline & & 2 & 3 & 4 & 5 \\
\hline \multirow{5}{*}{$\begin{array}{l}\text { Right Gluteus } \\
\text { Maximus }\end{array}$} & TOTAL $(n=200)$ & 8 & 67 & 65 & 60 \\
\hline & FEMALE $(n=83)$ & 5 & 41 & 27 & 10 \\
\hline & Frequency (\%) & 6.2 & 49.3 & 32.5 & 12.04 \\
\hline & MALE $(n=117)$ & 3 & 26 & 38 & 50 \\
\hline & Frequency (\%) & 2.56 & 22.22 & 32.48 & 42.74 \\
\hline \multirow{5}{*}{$\begin{array}{l}\text { Left Gluteus } \\
\text { Maximus }\end{array}$} & TOTAL $(n=200)$ & 4 & 55 & 63 & 78 \\
\hline & FEMALE $(n=83)$ & 4 & 33 & 29 & 17 \\
\hline & Frequency (\%) & 4.82 & 39.76 & 34.94 & 20.48 \\
\hline & MALE $(n=117)$ & 0 & 22 & 34 & 61 \\
\hline & Frequency (\%) & 0 & 18.8 & 29.06 & 52.14 \\
\hline \multirow[t]{5}{*}{ Abdominals } & TOTAL $(n=200)$ & 11 & 39 & 62 & 88 \\
\hline & FEMALE $(n=83)$ & 7 & 29 & 27 & 20 \\
\hline & Frequency (\%) & 8.43 & 34.94 & 32.53 & 24.1 \\
\hline & MALE (n =117) & 4 & 10 & 35 & 68 \\
\hline & Frequency (\%) & 3.42 & 8.55 & 29.91 & 58.12 \\
\hline
\end{tabular}

Table 4:- Comparison of Muscle length.

\begin{tabular}{|c|c|c|c|c|c|}
\hline & & Total $(n=200)$ & Female $(n=83)$ & Male $(n=117)$ & p-value \\
\hline \multirow[t]{2}{*}{ Spinal extensor } & Normal & 89 & $29(34.94 \%)$ & $60(51.28)$ & \multirow[t]{2}{*}{0.021} \\
\hline & Tight & 111 & $54(65.06 \%)$ & $57(48.72 \%)$ & \\
\hline \multirow[t]{2}{*}{ Right iliopsoas } & Normal & 33 & $10(12.05 \%)$ & $23(19.66 \%)$ & \multirow[t]{2}{*}{0.345} \\
\hline & Tight & 167 & $73(87.95 \%)$ & $94(80.34 \%)$ & \\
\hline \multirow[t]{2}{*}{ Left iliopsoas } & Normal & 41 & $11(13.25 \%)$ & $30(25.64 \%)$ & \multirow[t]{2}{*}{0.0325} \\
\hline & Tight & 159 & $72(86.75 \%)$ & $87(74.36 \%)$ & \\
\hline
\end{tabular}

Table 5:- Prevalence of Lower Crossed Syndrome among Male and Female

\begin{tabular}{|c|c|c|c|c|}
\hline & Female $(\mathbf{n}=\mathbf{8 3})$ & Male $(\mathbf{n = 1 1 7})$ & Total $(\mathbf{n}=\mathbf{2 0 0})$ & $\mathbf{p}$-value \\
\hline Affected & $\mathbf{3 0}(\mathbf{3 6 . 1 4 \%})$ & $\mathbf{1 4}(\mathbf{1 1 . 9 7 \%})$ & $\mathbf{4 4}$ & $\mathbf{0 . 0 0 1}$ \\
\hline Normal & $53(63.86)$ & $103(88.03 \%)$ & 156 & \\
\hline
\end{tabular}

\section{Conclusion:-}

This study has shown that prevalence of lower crossed syndrome in females were higher than males of the same age group. It was also found that there is insignificant difference in iliopsoas (left sided) tightness between males and females of the same age group. But there is significant difference in spinal extensor length, abdominals strength and bilateral gluteus maximus strength, Right iliopsoas length between males and females of the same age group, and females are more prevalent to develop weakness of these muscles. 


\section{Conflict of interest:-}

Authors report no conflicts of interest for this study. The authors alone are responsible for content and writing of this article.

\section{Funding:-}

No funds were received from any organization or person to carry out this project.

\section{Acknowledgement:-}

We are indebted to Dr. Abhishek Biswas (Director (Offg), NILD (Divyangjan) Kolkata for his kind consent/permission to carry out the project at NILD.

\section{References:-}

1. Alter MJ. Science of Flexibility. Champaign, IL.Human Kinetics; 2004.

2. Ashmen KJ, Swanik CB, Lephart SM. Strength and flexibility characteristics of athletes with chronic low back pain. J Sport Rehabil.1996;5:275-286.

3. Bergmark, A. 1989. Stability of the lumbar spine: A study in mechanical engineering. ActaOrthopScand Suppl. 230:1-54.

4. Burton AK,Tillotson KM. is recurrent low back trouble associated with increased lumbar sagittal mobility.J Biomed Eng. 1989;11:245-248.

5. Dhanani S.A survey on prevalence of lower crossed syndrome in young females. IJPSH.2014;1: 2249-5738.10

6. Feroz AH, Islam MN, Hasan M. The Bengali Short Form-36 was acceptable,reliable and valid in patient with rheumatoid arthritis.Journal of Clinical Epidemiology.2012:65(11)1227-1235.

7. FreseE.BrownM.NortonBJ.Clinical reliability of manual muscle testing.middletrapezious and gluteus mediusmuscles.Europe PMC.1987; 67(7):1072-1076.

8. Gajdosik R,Rieck M A,Sullivan D K,Wightman S E.Comparison of four clinical tests for assessing hamstring muscle length.JOSPT,1993;18(3):614-618.12

9. G T Jones, G J Macfarlane. Epidemiology of low back pain in children and adolescents. Arch Dis Child 2005; 90:312-316.

10. Graven-Nielsen, T, P. Svensson, and L. Arendt-Nielsen. 1997. Effects of experimental muscle pain on muscle activity and co-ordination during static and dynamic motor function. ElectroencephalogrClinNeurophysiol105(2): 156-64.6

11. Helewa A, Goldsmith CA, Lee P, Smythe HA, Forwell L. Does strengthening the abdominal muscles prevent low back pain- a randomized controlled trial. Journal of Rheumatology,1999:26:1808-15

12. Janda,V.1978.Muscles, central nervous regulation and back problems. In Neurobiological mechanisms in manipulative therapy, ed. I.M. Korr, 27-41. New York: Plenum Press.5

13. Janda, V. 1986b. Some aspects of extracranial causes of facial pain. J Pros the t Dent 56(4): 484-7.

14. Janda V. 1987. Muscles and motor control in low back pain: Assessment and management. In Physical therapy of the low back, ed. L.T. Twomey, 253-78. New York: Churchill Livingstone. 1

15. Janda, V. 1989b. Impaired muscle function in children and adolescents. Journal of Manual Medicine 4(3):15760 .

16. Janda, V. 1993. Muscle strength in relation to muscle length, pain, and muscle imbalance. In Muscle strength. Vol. 8 of International perspectives in physical therapy, ed. K. Harms-Ringdahl, 83-91. Edinburgh:Churchill Livingstone.

17. Janssen J.HeymsfieldSB.WangZM.RossR.Skeletal muscle mass and distribution in 468 men and women aged 18-88 years.JAppl Physiol.2014;116(10):1342.

18. Jones GT, Macfarlane GJ. Epidemiology of low back pain in children and adolescents Arch Dis Child 2005; 90:312-316.

19. Kendall, F.P., E.K. McCreary, and P.G. Provance. 1993.Muscles. Testing and function. 4th ed. Baltimore: Williams \& Wilkins.

20. Kisner C .Colby L A.Therapeutic exercise. $5^{\text {th }}$ ed.JAYPEE.2007.pg 240.

21. Luyerink. VrugtA. The Contribution of Bodily Posture to Gender Stereotypical Impressions. Social Behavior and Personality.2000;28(1):91-104.

22. Magee D .orthopedic physical assessment.WB Saunders 4th Ed .2002 - pg 478, 483, 631.

23. Maughan RJ; Watson JS; Weir J (May 1983). Strength and cross-sectional area of human skeletal muscle".The Journal of Physiology.1983. 338: 37-49. 
24. Mills M. FrankB. GotoS.BlackburnT. ClarkM. AguilarA. FavaN. Effect of restricted hip flexor muscle length on hip extensor muscle activity and lower extremity biomechanics in college aged female soccer players.IJSPT.2015; 10(7):946.

25. Morey J., Cydne Fuller, Jessica Marshall, Amanda Wright, MPH,William J. Hanney, The reliability and concurrent validity of scapular plane shoulder elevation measurements using a digital inclinometer and goniometer.2012;28(2):161-168.11

26. Norkin C C,White D J. Measurement of joint motion-a guide to goniometry $3^{\text {rd }}$ ed.,Philadelphia,F.A Davis Company 2004:p.334-336,340,

27. Opar DA, Williams MD, Shield AJ. Hamstring strain injuries: factors that lead to injury and re-injury. Sports Med. 2012;3:209-226.

28. Parashar P, Arunmozhi R, C Kapoor. Prevalence of low back pain due to abdominal weakness in collegiate young females. 2014.2(1).

29. Robinson H S.Mengshoel AM. Assessments of lumbar flexion range of motion. SPINE Volume 39 , Number 4 , pp E270 - E275.

30. Sahrmann, S.A. 2002. Does postural assessment contribute to patient care? J Orthop Sports PhysTher32(8): 376-79.

31. Sararaks S, Azman A B, Low L L Validity and Reliability of the SF.36: The Malaysian Context Med J Malaysia 2005 June:60(2):163-7

32. Schoonman, DC. Lower back pain: Chronic lower back pain and lower Crossed Syndrome.

33. Scott C Cuthbert, George J Goodheart,Jr.on the reliability and validity of manual muscle testing.2007;25(4);1746-1340.

34. Sherrington, C S . 1907. On reciprocal innervation of antagonistic muscles. Proc R SocLond B BiolSci79B: 337.7

35. Sinha R, Van den, Heuvel WJ. Validity and reliability of MOS short form health survey (sf-36) for use in India. Indian J Community Med 2013; 38: 22-6.13

36. Vella C.M.S. Kravitz L. Gender Differences in Fat Metabolism". The University of New Mexico.2014. 